Thorax (1961), 16, 197.

\title{
GASTROPLASTY
}

\author{
BY \\ J. LEIGH COLLIS \\ From the Queen Elizabeth Hospital, Birmingham
}

(RECEIVED FOR PUbliCATION MAY 1, 1961)

In 1957, an operation called gastroplasty was described which had been designed to help patients with hiatus hernia associated with short oesophagus (Collis, 1957a and b). Experience with this operation now extends over six years and it seems appropriate at this stage to review the results.

The general plan behind this operation is based on the assumption that all the troubles suffered by patients with any sliding type of hiatus hernia are due to reflux of gastric juice. It is further believed that if reflux is prevented the patient will usually be improved even though the main symptom be dysphagia. These assumptions can easily be put to the test in patients with sliding hiatus herniae and oesophagi of normal length. The operation of plastic repair as described by Collis, Kelly, and Wiley in 1954, with follow-up results in 1961, is very effective in controlling reflux and gives a parallel improvement in all symptoms (Collis, 1961). When, however, the oesophagus is short, the irreducible portion of stomach within the chest makes the operative plan much less effective. In this circumstance it is impossible to get an acute angle of implantation between the oesophagus and the fundus of the stomach ; further, the bulk of the stomach tissue between the two halves of the right crus makes suturing in this area less effective.

In gastroplasty the bulky stomach pouch is reduced to a tube. This provides two benefits. First, the crura can now be sutured around a tube of a size similar to a normal oesophagus; and, secondly, the new tube can be fashioned to enter the stomach at an acute angle similar to the angle of entry of a normal oesophagus.

The method by which the stomach is fashioned to allow of this is shown in Figs. 1, 2, 3, and 4. In effect a tube of stomach is used to lengthen the oesophagus. The extra length makes it possible for the tube to enter the stomach at an acute angle and without tension. When the operation has been completed the patient is left with stomach tissue above the diaphragm. It might be said that he still has a hiatus hernia, but the difference is that now reflux from the main body of the stomach has been controlled.

The theoretical assumptions for supposing that the gastric tube within the chest would not prevent a good result were put forward in Thorax of September, 1957, but now it is possible to put the statements to the more exacting tests of practice (Collis, 1957a and b). Another aspect of the operation is that the area of the cardia, and in many cases the stricture area, has not been excised. Leaving this can only be satisfactory if the changes are reversible and are able to settle as a result of the control of reflux provided by a gastroplasty.

\section{Operative Details}

There are two essential parts to this operation ; the first is the fashioning of the stomach in accordance with Figs. $1-4$, and the second is a plastic repair of the oesophageal hiatus. This entails suturing of the fibres of the right crus in such a way as to support the acute angle of implantation between the gastric tube and the main body of the stomach. The operative technique as described in 1957 has been modified and simplified with the result that the operation is now shorter and less upsetting to the patient. Dissection in the area of the cardia within the chest has been abandoned. It does no good and may be dangerous. The operation is now done via an abdomino-thoracic incision which is the same approach as I use for all hiatal hernia repairs. The whole procedure is done from the under surface of the diaphragm, and while the division into the stomach is not started so high up it is taken lower. This, it is felt, gives a better angle of implantation than previously. Originally a point was made of narrowing the stomach tube very markedly; but this practice has given early post-operative trouble and late dysphagia, and it is now felt that extra length of the tube controls reflux almost as well as narrowing the tube. It is also found that, while narrowing the stomach tube causes permanent dysphagia, narrowing the hiatus may cause early 


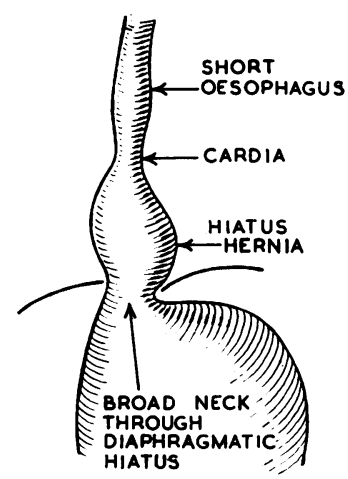

FIG. I
FIG. 2

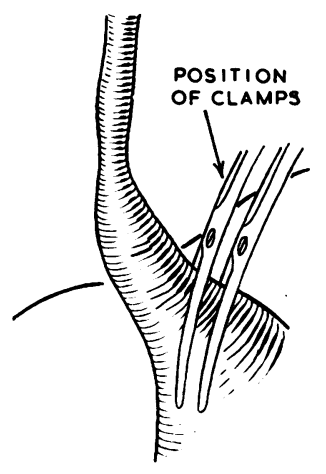

FIG. 1.-This represents the well-known arrangement of a hiatus hernia with a short oesophagus.

Fig. 2.-The stomach is here pulled down as far as possible and clamps applied so as to reduce the size of the stomach tissue passing up into the chest.

post-operative dysphagia, but this will always improve spontaneously.

The patient is placed on his back on the operating table with the left side raised with a sand bag. A left abdomino-thoracic incision is made from the umbilicus and along the seventh intercostal space to the mid-axillary line. The abdomen and chest are opened. The diaphragm is incised so as to avoid damage to the phrenic nerve branches. For this purpose the diaphragm is cut close to the costal margin until the area is reached opposite the division between the posterior and lateral branches. In this area the incision is carried centrally to a point just short of the central tendon. This angulated incision

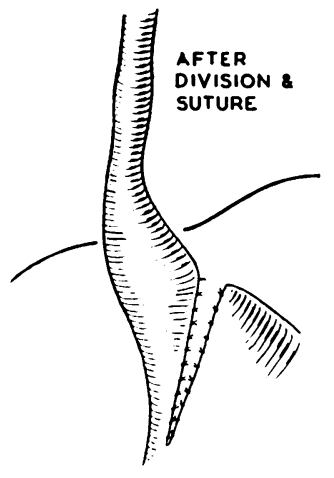

F IG.3

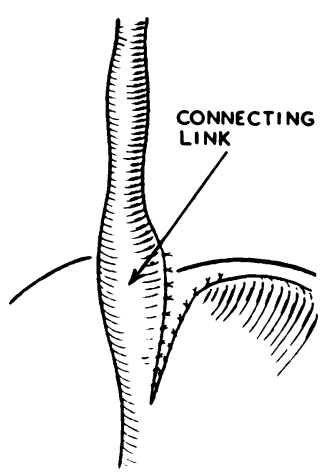

FIG. 4
FIG. 3. - The stomach has now been divided between the clamps and the edges oversewn and invaginated.

FIG. 4.-A plastic repair of the oesophageal hiatus is now performed around the narrow gastric tube. This mancuvre retains in place the acute angle of implantation between the gastric connecting tube and the main body of the stomach. is rather awkward to make and to sew up, but is considered a marked improvement because it results in a normally functioning diaphragm after operation. The muscle fibres of the right crus are exposed. The stomach passing up into the chest is isolated, the lesser sac is opened, and the left gastric vessels are divided. This allows of a clean peritoneal-covered surface being made available on both the back and the front of the stomach. A stomach tube is now passed by the anaesthetist. Originally size No. 9

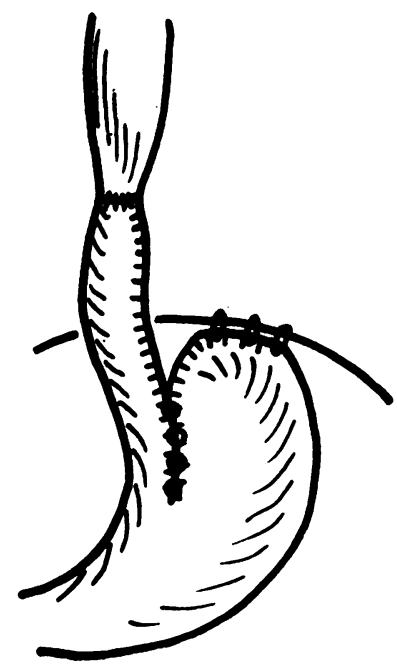

FIG. 5.-This figure was kindly supplied by Professor Rapant and shows a modification of my technique (Rapant and Schwarzer, 1960). The only major variation is excision of the ${ }_{t}$ stricture. This is considered to be seldom if ever necessary.

(English gauge) was advised, but a larger size is now used to ensure that the stomach tube is not narrowed too much (size No. 12 English).

The clamps are now applied parallel with the lesser curve. They are placed as high on the gut as possible from below the diaphragm and are taken as far down towards the pylorus as their length will allow. Stevenson clamps are now preferred to the ParkerKerr type previously used, as they produce less crushed tissue. Further improvement could be effected here by an even less traumatic clamp. The stomach is divided between the clamps (Fig. 3) and the cut surfaces are oversewn and invaginated with continuous catgut.

The position is now that there is a gastric tube passing through the hiatus which is similar in size to the oesophagus. This tube passes well down below the hiatus before entering the newly enlarged fundus (Fig. 4). A plastic repair of the two halves of the right crus is now performed by suturing them from above downwards. This retains in place the newly instituted good angle of implantation between the stomach tube and the fundus. Rapant and Schwarzer (1960) have added suturing of the connecting tube to the fundus, but this should not be necessary (Fig. 5). 
Sutures are placed between the fundus and the diaphragm as they also suggest. It will be seen also that they excise the stricture. Such a step might have a place in some cases, but it is not thought desirable as a general plan, and it greatly increases the magnitude of the operation and the potential complications.

After suturing the fundus to the under surface of the diaphragm the wound is closed with intercostal drainage. While the abdomen was open a chance will have been taken to check the rest of the stomach, the duodenum, and the gall bladder.

\section{Clinical Material}

This operation was used on 32 occasions between April, 1955, and January, 1960. Of these patients, 30 are available for review. This reduction by two is due to the failure to get any reply from one patient who lives in Iraq and the loss of all notes of another patient.

The 30 remaining patients all had obvious shortening of the oesophagus and present a wellrecognized picture on barium swallow. Typical examples of such barium studies are shown in Figs. 6, 7, and 8 . The general clinical picture varied from case to case, and the following subdivision has been made of the group:

\begin{tabular}{|c|c|c|c|c|}
\hline \multirow{5}{*}{$\begin{array}{l}\text { Group W } \\
\text { Group X }\end{array}$} & \multirow{5}{*}{$\begin{array}{l}\text { No dysphagia } \\
\text { With dysphagia }\end{array}$} & & \multicolumn{2}{|c|}{$\begin{array}{r}\text { No. of } \\
\text { Patients }\end{array}$} \\
\hline & & 1 Ulcer at cardia &. & 5 \\
\hline & & 2 Oesophagitis & $\cdots$ & 3 \\
\hline & & $\begin{array}{c}3 \text { Oesophagitis with major } \\
\text { rowing. }\end{array}$ & $\begin{array}{c}\text { nar- } \\
. .\end{array}$ & 10 \\
\hline & & 4 Local stricture at cardia & .. & 8 \\
\hline & & & al ... & 30 \\
\hline
\end{tabular}

In Group $\mathrm{W}$ the most pressing symptom was haematemesis in three cases; in the other two vomiting was most prominent in one and heartburn in the other.

In the remaining 25 patients of Group $X$, dysphagia occurred with varying severity. Group $2 \mathrm{X}$ had the least dysphagia and the most symptoms of reflux. In Group $1 \mathrm{X}$ a peptic ulcer was present on the cardia with little other evidence of oesophagitis. On barium swallow the cardia looked narrow, but under anaesthetic no obstruction was found. It seems reasonable to presume that the dysphagia was due to spasm associated with the ulcer and that the spasm was protective to the oesophagus against further oesophagitis. This condition should be readily reversible.

Groups $2 \mathrm{X}$ and $3 \mathrm{X}$ are similar except in respect of the degree of narrowing found at oesophagoscopy. In both there was a length of oesophagitis extending up from the cardia with associated narrowing in the same area seen on barium swallow. It seems reasonable to presume that in these cases there has been no tight area at the cardia which has been protective against reflux of acid, and that this has resulted in more extensive oesophagitis. There has been, however, some general obstruction, so that the oesophagitis has been limited to a few inches. Since the obstruction in Group $2 \mathrm{X}$ mainly goes under anaesthesia it is likely that this is largely due to spasm. In Group $3 \mathrm{X}$ the cause of the obstruction is more controversial, but it seems reasonable to say that oedema and the laying down of fibrous tissue play their parts. The degree to which the obstruction is due to fibrous tissue may be expected to have a bearing on the reversibility of the lesion. In Group 4X there was marked obstruction at the cardia which always required dilatation. The tight stricture had been protective against oesophagitis higher up. It seems likely that the cause of the obstruction in this group is a combination of spasm, oedema, and fibrosis.

It seems that a patient may go on for years with minor heartburn associated with the hernia and short oesophagus but that once symptoms become prominent he will fall into one of the above five groups and that he will always remain in the same group. That is to say, if he first responds with serious symptoms but no dysphagia, this will always be his pattern. Similarly, if he has poor protection and oesophagitis this will always be his pattern. In fact this situation need cause little surprise. In one way the groups can be influenced, and this is by oesophagoscopy and dilatation. By this means it is particularly noticeable that cases of Group 4X can be converted to Group 3X. The opposite is never possible.

One patient in Group 3X and three in Group $4 \mathrm{X}$ had been troubled with dysphagia from birth. The age distribution is shown in Table $I$.

TABLE I

AGE DISTRIBUTION

\begin{tabular}{c|c}
\hline Age (Years) & No. of Patients \\
\hline $0-10$ & 1 \\
$10-20$ & Nil \\
$20-30$ & Nil \\
$30-40$ & 4 \\
$40-50$ & 1 \\
$50-60$ & 8 \\
$60-70$ & 14 \\
70 and over & 2 \\
\hline
\end{tabular}

The small numbers in the younger age groups may be partly due to the nature of my practice, but the general picture has considerable bearing on the problem. The frequency with which the problem presents in the seventh decade makes it highly desirable to recommend as small an operation as possible. 

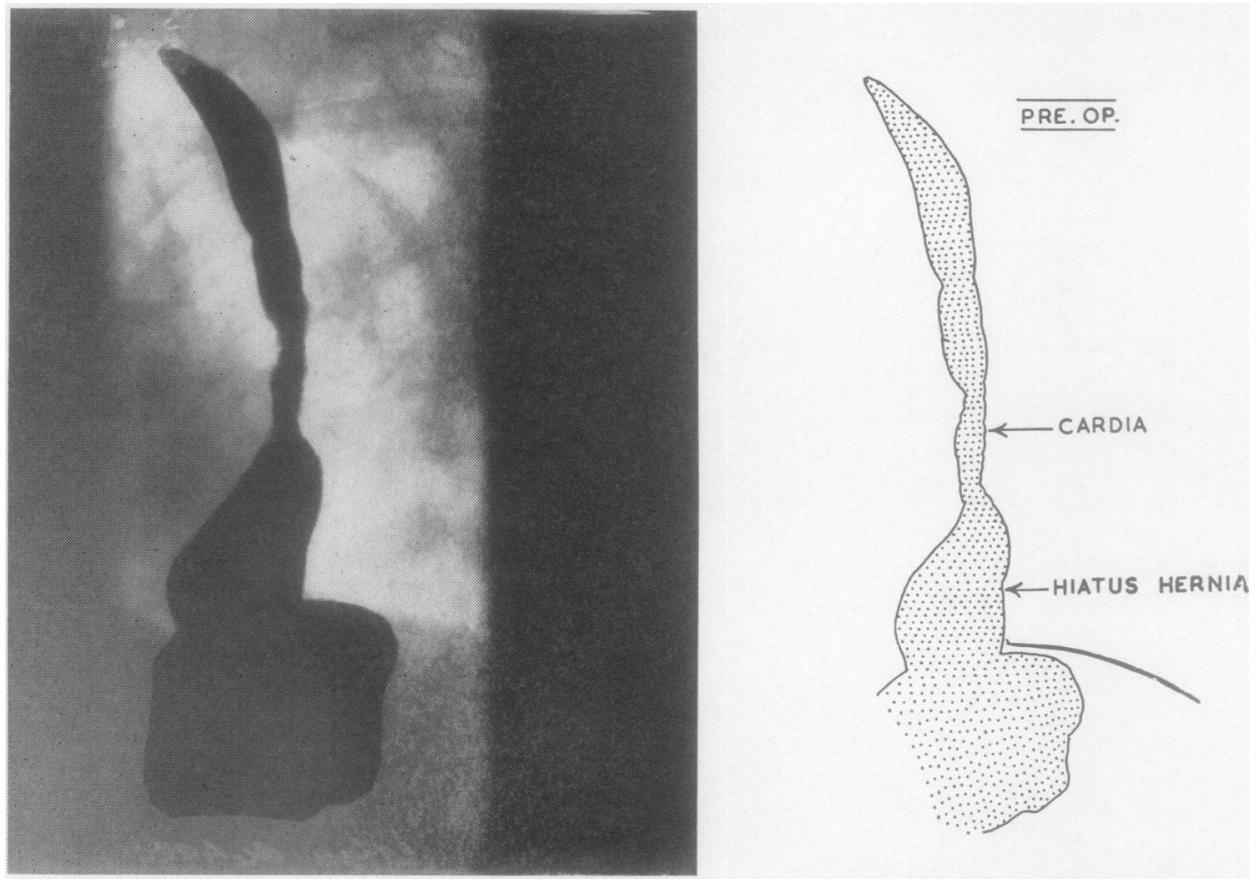

Fig. 6.-A barium swallow showing the short oesophagus and gastric pouch within the chest. The wide neck of gastric tissue at the oesophageal hiatus is clearly shown.
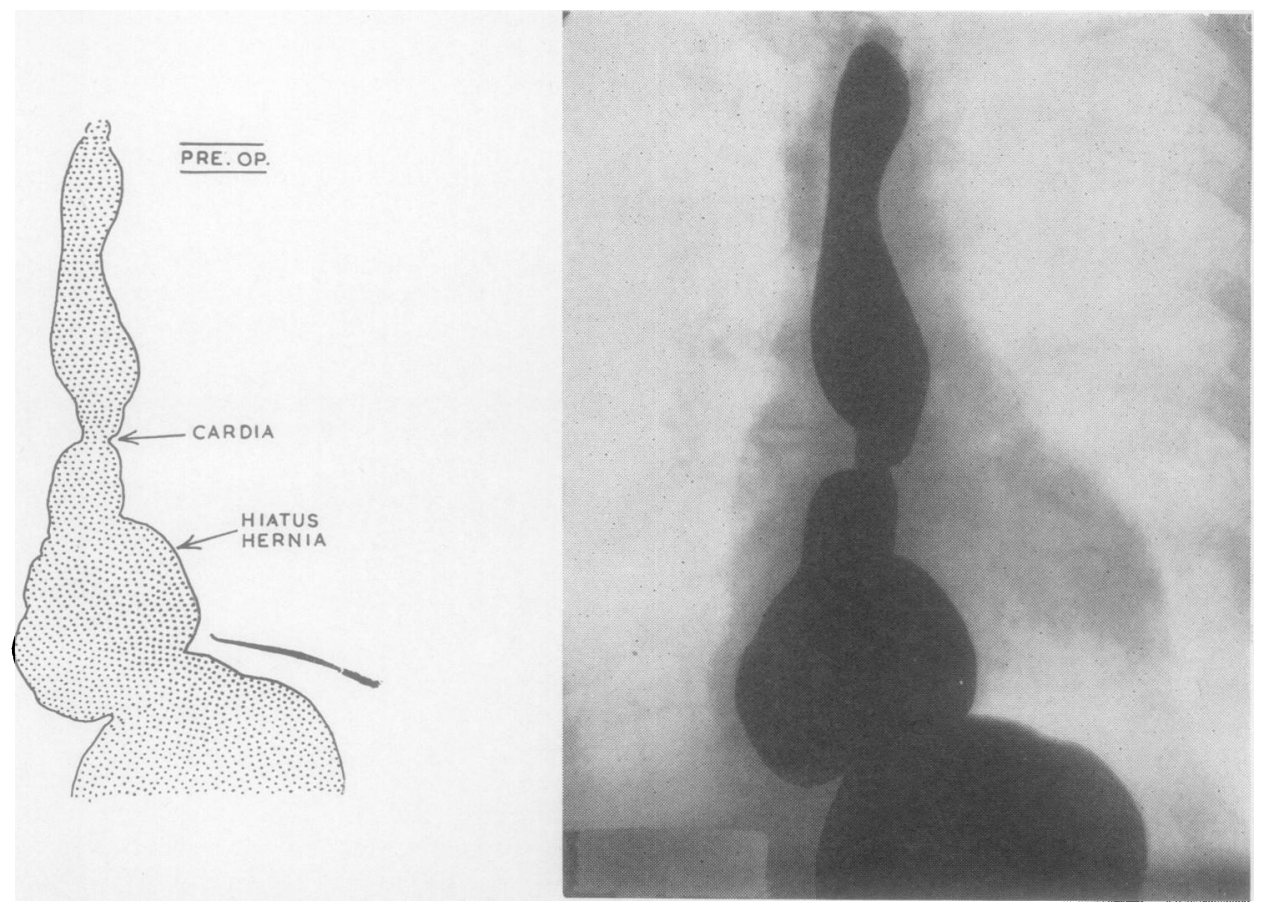

FIG. 7.- This shows the same points as seen in Fig. 6, but from the antero-posterior aspect. 

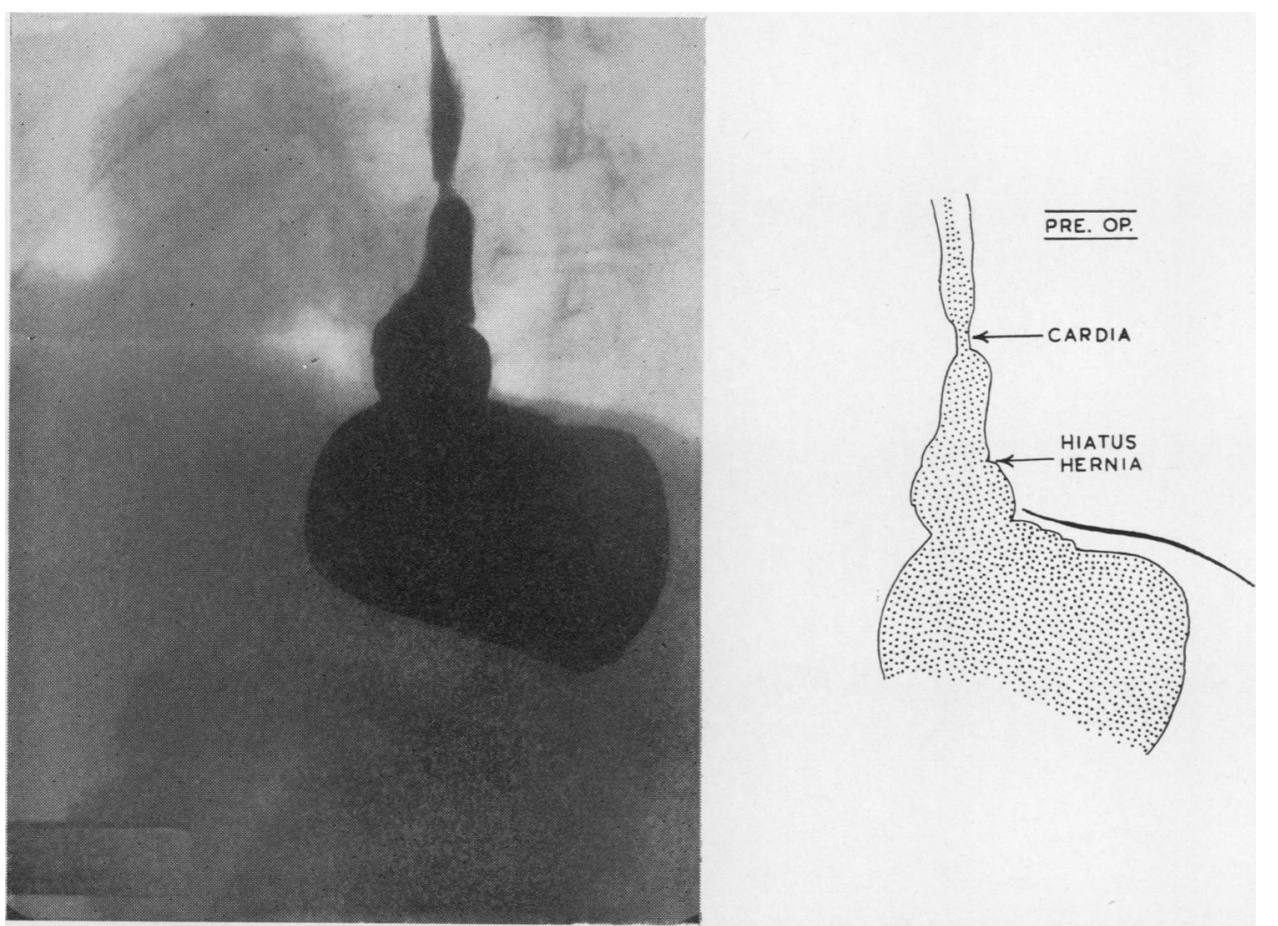

FIG. 8.-Again the same type of picture as seen in Figs. 6 and 7 is shown. The only way in which any of these pictures vary is in the degree of narrowing at the cardia.
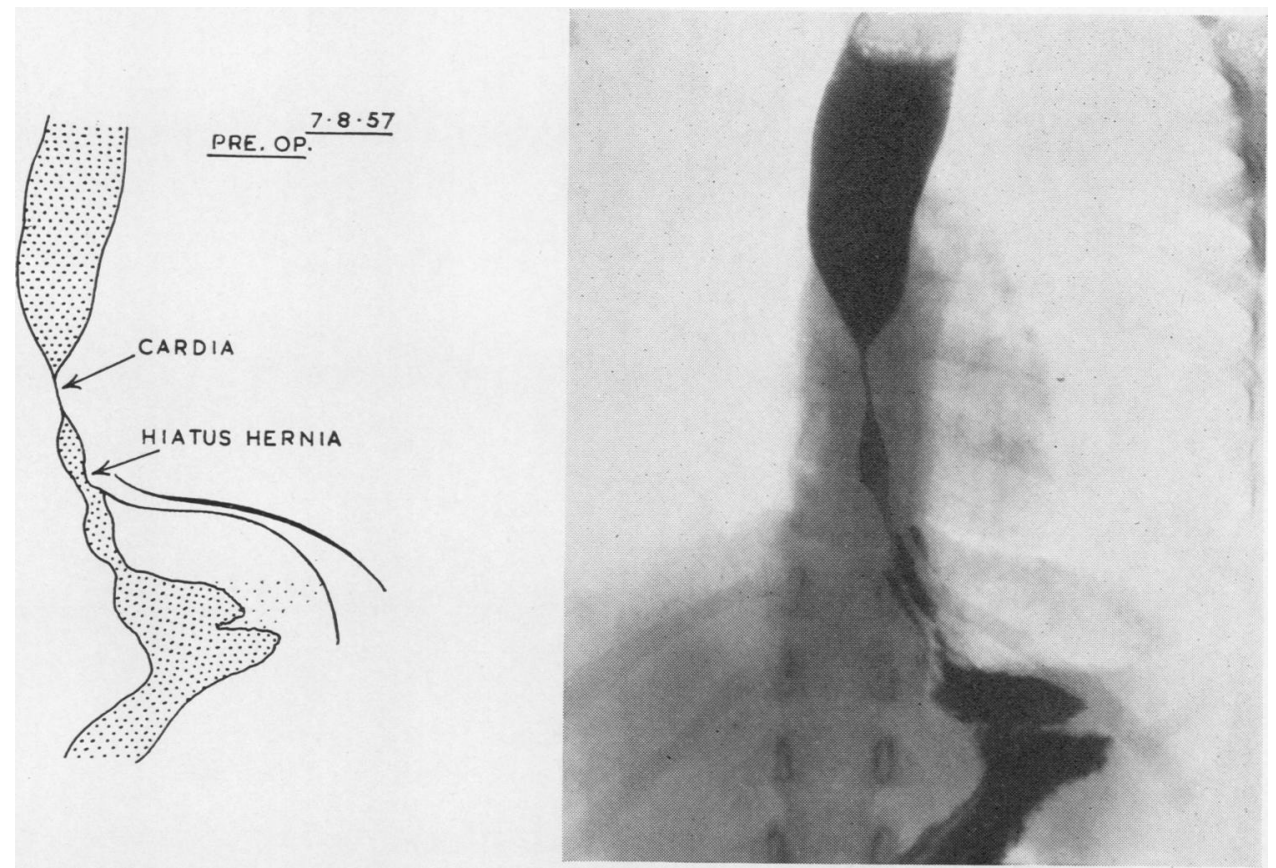

FIG. 9.-This is a pre-operative film similar to Figs. 6, 7, and 8, but here the narrowing at the cardia is even more marked. 

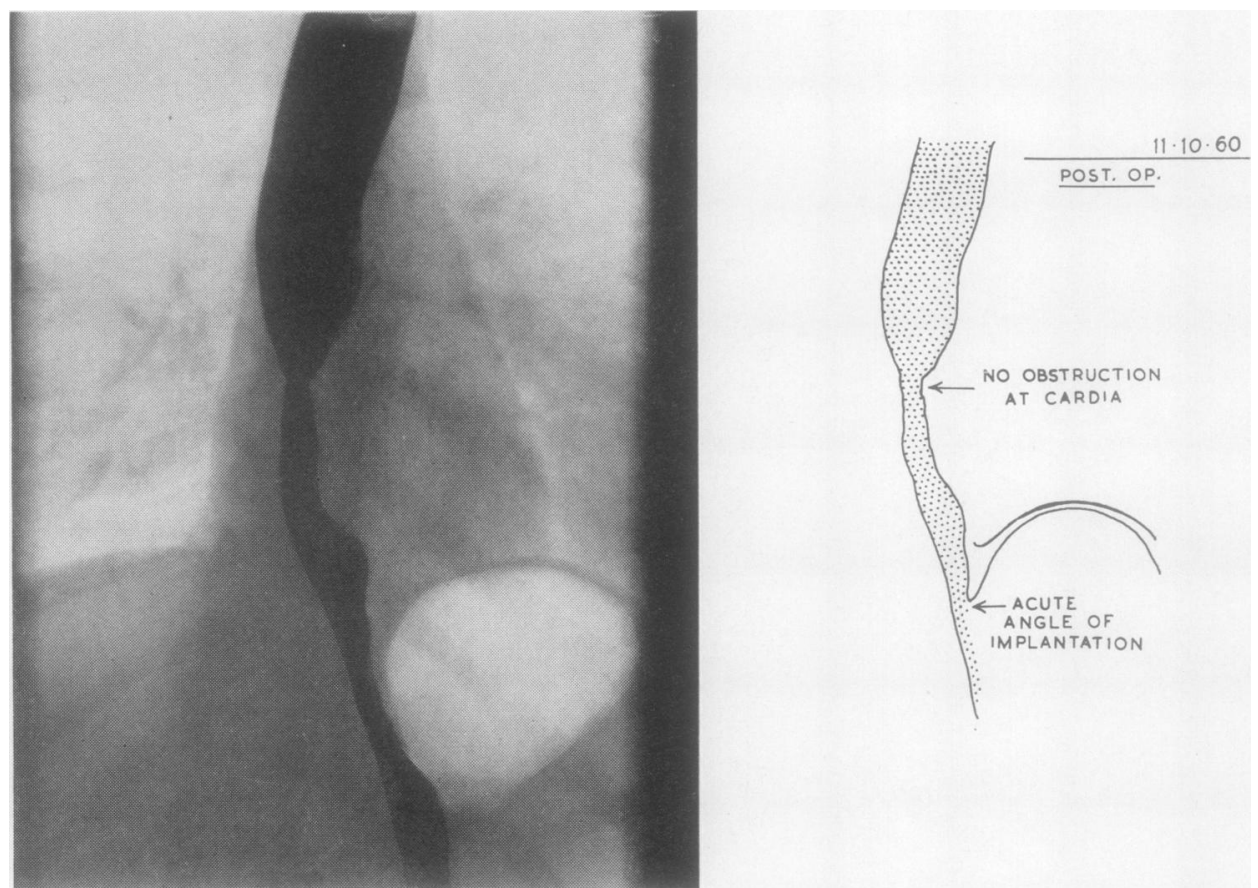

FIG. 10.-The position shown here is after gastroplasty in the same patient as in Fig. 9. The cardia shows less obstruction. The gastric connecting tube joins the oesophagus to the main body of the stomach. The connecting tube joins the stomach at an acute angle.
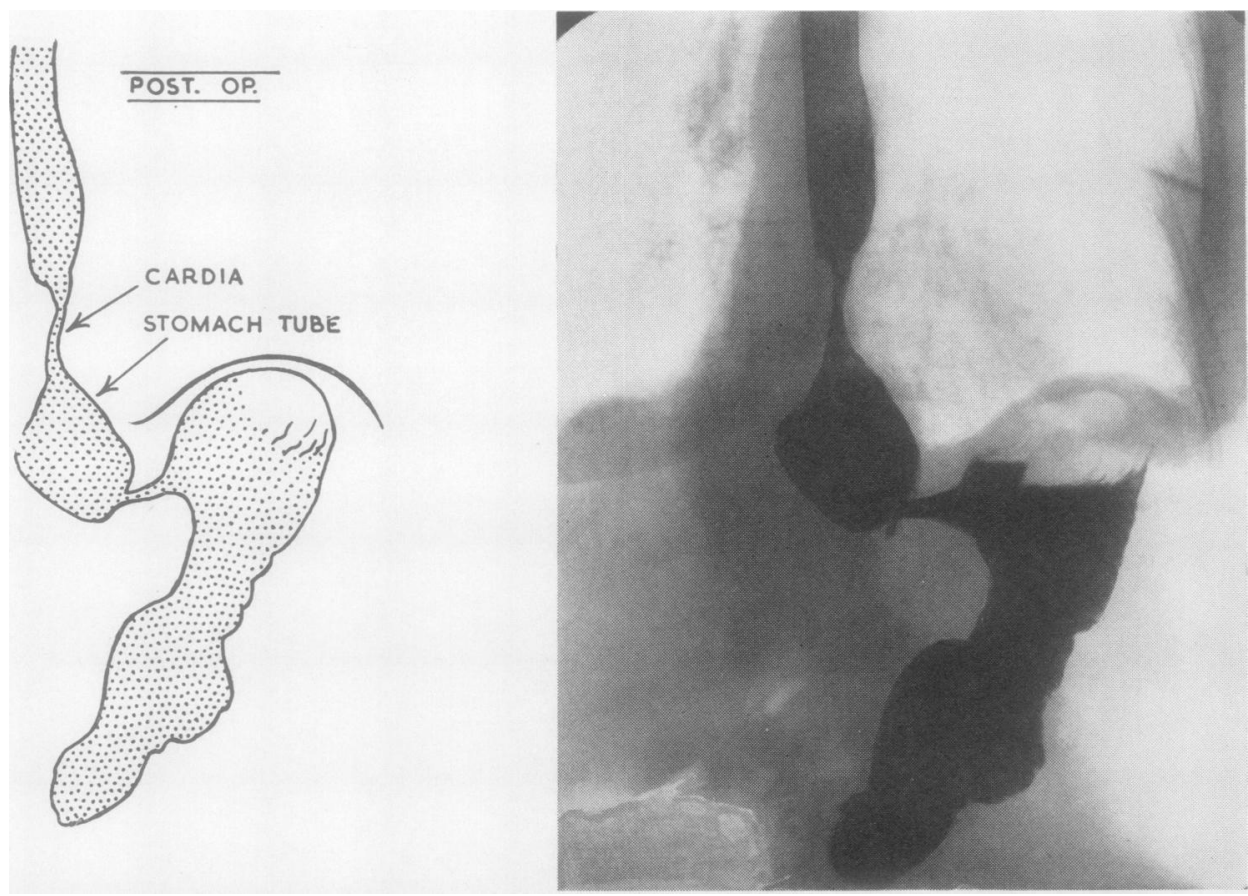

FIG. 11.-A gastroplasty has been performed. The cardia is shown within the chest. The gastric connecting tube is rather distended and untidy. This is apt to become like this if the gastric connecting tube has been made too narrow in the region of the hiatus. 

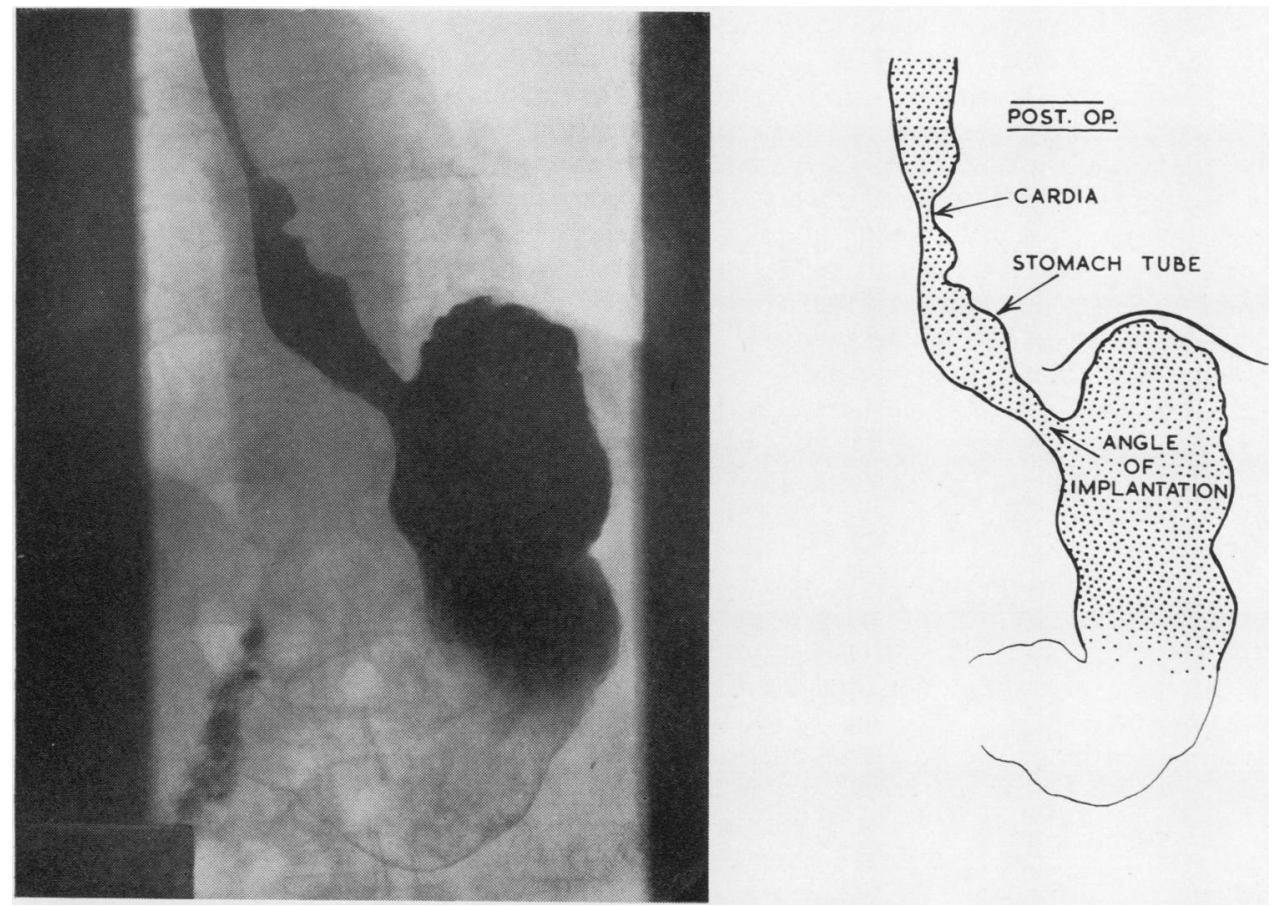

FIG. 12.-Again the picture after gastroplasty. The size of the gastric connecting tube is satisfactory and a good angle of implantation has been effected.
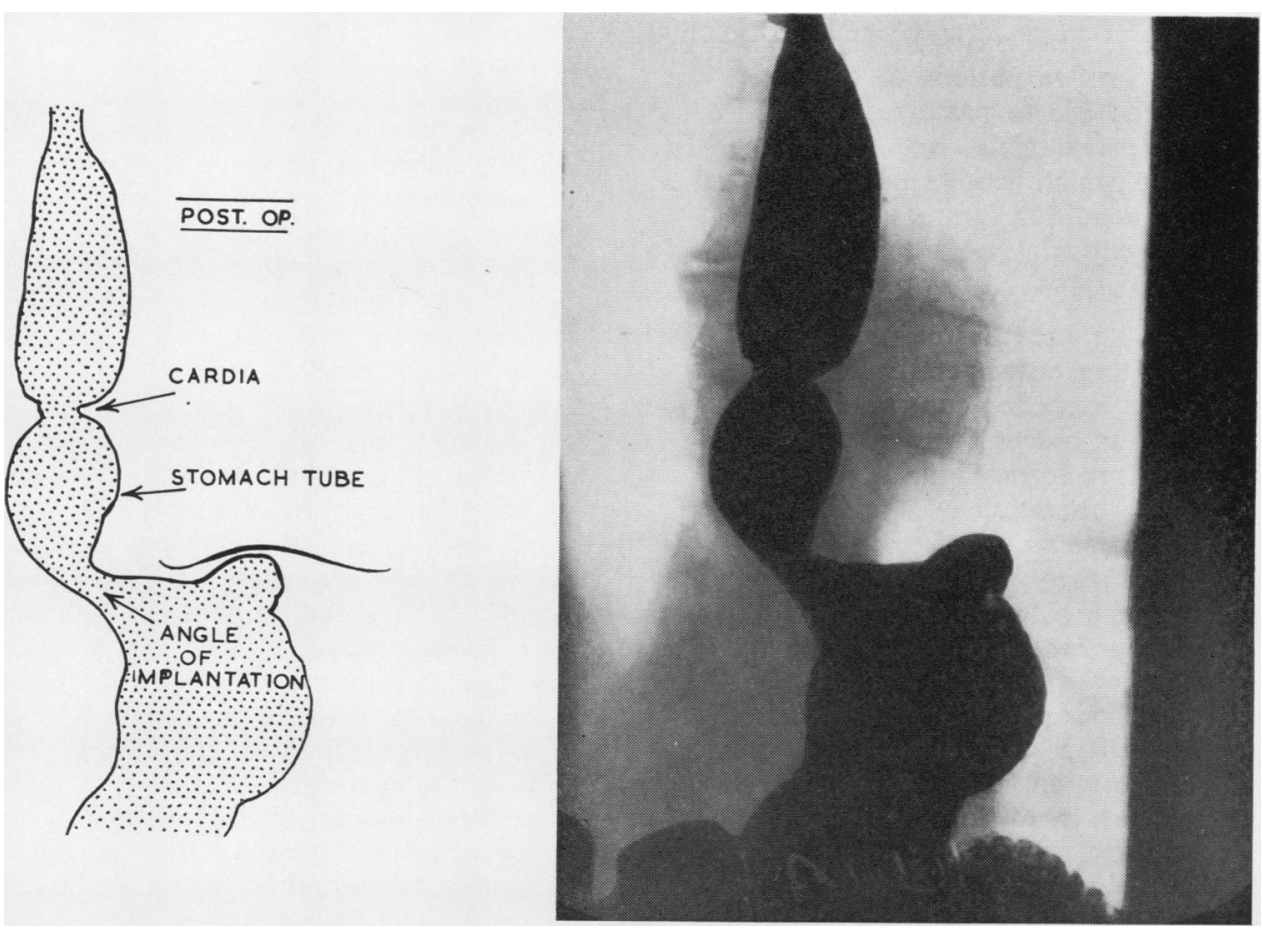

FIG. 13.-A further picture of the situation after gastroplasty. The angle of implantation between the connecting tube and the main body of the stomach is not so acute in this case. This resulted in rather poor control of reflux. 
In two patients dysphagia started suddenly following an abdominal operation. This type of history, or the variant of the sudden onset of the dysphagia following labour, is well recognized. In this circumstance a short oesophagus cannot have been produced so suddenly, and it must be that the condition was already present although not producing major symptoms. This is supported by the presence of a previous history of heartburn in all but four cases out of the whole group.

From this clinical material it would seem reasonable to suppose that a hiatus hernia with short oesophagus has been present in all cases from birth but that major symptoms may be delayed for many years. The onset of symptoms is due to free reflux of acid from the stomach which has previously been prevented in spite of the hiatus hernia. The control in earlier years has been due to the strength of the crural muscle. This muscle is working under considerable difficulty because of the hiatus hernia, and its effectiveness may be removed by the ageing process which may be speeded up by the conditions at a major operation or during labour. If this control never broke down the patient would never develop major symptoms. Once major reflux is occurring improvement may be expected if control of reflux is re-established. The benefit to the patient will be limited by the degree to which reflux has produced irreversible changes. From the picture of the pre-operative pattern of the cases studied it seems reasonable to presume that the majority of lesions are reversible, but that there may be some cases in which fibrosis has been so gross as to make the condition irreversible.

\section{Post-operative Results}

The following are the questions I have asked myself in judging post-operative results.

(1) Does the operation control reflux ? (2) Does control of reflux relieve symptoms? (3) To what extent is stricture formation a reversible process? And (4) is the operation well tolerated ?

If only everything was exactly as one would have wished many very interesting questions would have been solved by these results. Unfortunately certain technical problems inevitably have arisen, so that even now the operation is not doing perfectly all that is planned for it. When a patient is doing badly it is difficult to be certain whether it is the operation or the way it has been performed that is at fault. In spite of these difficulties in the way of the interpretation of the results, a broad pattern can be seen. Further, the effects are so regular and repeatable that it does seem possible to speak with considerable conviction about results which are being produced.

The patients have been followed up from operation to March, 1961, which gives postoperative observation for at least 12 months. Barium swallow examinations have been made on discharge and annually after that. In certain cases late oesophagoscopy has been performed.

The general pattern has been that improvement has been the rule, but that the patients usually are not symptom-free. If dysphagia has been the problem the patient may be very pleased but will admit that some degree of care has to be taken. According to the degree of improvement of symptoms and signs in each individual case, the patients have been placed in one of five grades: A excellent, B good, C improved, D bad, and $\mathrm{E}$ died as a result of operation. These grades can be combined with the various groups of the condition, and the result is set out in Table II.

TABLE II

RESULTS ACCORDING TO POST-OPERATIVE GRADING

\begin{tabular}{c|c|cccc|c}
\hline Grade & Group W & Group 1X & $2 \mathrm{X}$ & $3 \mathrm{X}$ & $4 \mathrm{X}$ & Total \\
\hline $\mathbf{A}$ & 4 & 3 & 2 & 2 & 5 & 8 年 \\
B & 1 & 1 & 1 & 3 & 3 & 7 \\
C & & & & 1 & & 1 \\
E & & & 2 & & 2 \\
\hline Totals & 5 & 4 & 3 & 10 & 8 & 30 \\
\hline
\end{tabular}

The success of the operation may well be judged by the degree to which in each group results can be placed in groups $A$ and $B$. These represent highly satisfied patients, and it will be seen that 75 to $100 \%$ of patients in Groups W, 1X, and $2 X$ reach this standard. The only falling off is represented by two patients classed as improved. In one of these it was clearly an operative technical fault, while the other was difficult to understand as the technical result seemed excellent. In groups $3 \mathrm{X}$ and $4 \mathrm{X}$ the degree to which they reach the $A$ and $B$ sections are not so good. In group $3 X$ only $50 \%$ do this, while in group $4 \times 62 \%$ reach the A or B standard. The reasons for the failure to reach the $A$ or $B$ grade was in two cases death. One was an early post-operative death and one from continued postoperative sepsis finally resulting in a brain abscess. In three cases technical defects resulted in obstruction at the hiatus. One patient also had severe Parkinsonism, and this is probably the only reason for continued difficulty. In the remaining two cases dysphagia had been present from birth, and it was thought for some time that the changes here 
were so severe as to be irreversible. However, after three years both patients are materially better. This tendency to delayed improvement has been noted several times. The overall picture is that $63 \%$ of cases have been put into grades A or B. This is a fairly good rate of improvement, but it is further improved if the cases are subdivided into the first 15 and the second 15 operated upon. The $A$ or $B$ rate in the second 15 is then shown to be $80 \%$ as against $47 \%$ in the first 15 .

Barium swallow at the end of one year showed that the degree of control of reflux is not nearly as good as can be effected in hiatus hernia without short oesophagus using my own operation. Some reflux could be produced in practically all cases by determined efforts, and "good control" only means that these efforts had to be strenuous. The results are given in Table III.

TABLE III

BARIUM SWALLOW AT ONE YEAR

$\begin{array}{llllllr}\text { Good control } & . & \ldots & \ldots & \ldots & . . & 13 \\ \text { Some control } & . & . . & . . & . . & . . & 8 \\ \text { Free reflux } & . & . . & \ldots & . . & . . & 6\end{array}$

In the earlier operations the stomach tube was made very narrow in the region of the hiatus, and there is no doubt that this helped to control reflux. It also led to a considerable amount of dysphagia from the narrowing and as a result defeated its own object. In the later cases general results are better, but reflux is not quite so well controlled. On balance the modification seems an advantage, although there is probably still room for improving the surgical technique in this respect.

The general picture of the barium swallow is shown in Figs. 9-13. The gastric connecting tube is shown. In the early cases, when the tube was materially narrowed at the lower end, this tube became unduly blown up.

Oesophagoscopy has been done after operation in 15 patients. In seven of these it has only been to check the local situation, while in eight it has been because of persistent and troublesome dysphagia. The results from these examinations have left no doubt that oesophagitis is relieved by reduction in reflux and, further, that all strictures met with so far can ultimately be brought under control so that a reasonable diet can be taken.

\section{Progress of the "Stricture"}

The usual post-operative course is that in spite of the restricted diet the patient is convinced of an immediate improvement in swallowing. Some tightness may exist from suture of the right crus, but this steadily eases off over the next month.
Finally, most patients, as has already been said, are not quite perfectly cured but are so much improved as to be quite contented. Eight patients required further oesophagoscopies for dysphagia, but in three of these the stricture was at the gastroplasty angle and can therefore only be considered as a technical fault. In five, trouble at the cardia within the chest continued. As might be expected, three of these patients were in Group $3 \mathrm{X}$ and two in Group 4X.

Treatment has been by dilatation and by prednisone. In two instances, particularly, it was felt that excision would have been a better plan, but now after three years from operation these patients are going for periods of at least six months between dilatation. Both these two particularly resistant cases gave a history of dysphagia from birth. One was in Group 4X and one in Group 3X. The feeling with this group is now that excision is not necessary and that the practice of simple gastroplasty in all cases should be continued.

\section{CONCLUSIONS}

One of the great merits of gastroplasty is that it is a relatively simple operation with a low operative mortality. Its next merit is that it leaves the patient's digestive tract in a fairly normal arrangement so that such troubles as anaemia or dyspepsia need not be feared. Further, if in any case the operation should be found to have been quite unsatisfactory the patient has not been subjected to any terrible risk and some other procedure could still be done. In fact, no further procedure has been necessary in any of the 30 cases reported, and the general results, though perhaps not perfect, are far better than anything else I have experienced. It is appropriate to make a special note that the 30 cases represent only the most resistant problems. It is the regular practice to attempt control with medical measures in all these patients before advising gastroplasty. It is felt that the two parts of the procedure, i.e., gastroplasty and a plastic repair of the hiatus from above downwards, should be done, but it has been interesting to hear that Bingham (1958) gets good results with gastroplasty followed by an Allison (1951) type of repair of the hiatus.

From what has been said in the review of the surgical results, it will be seen that straightforward answers to the four questions put before starting on the clinical results are very difficult to give. Dealing with the first question of control of reflux, it must be admitted that so far it has only been possible to reduce reflux. Really satisfactory control has been the exception. As to the second 
question, it seems reasonable to assume that the only reason for benefit is the control of reflux. In view of the general improvement in swallowing that has occurred it seems reasonable to assume that control of reflux does relieve dysphagia at least in part. With regard to the third question, there seems no doubt that some cases of dysphagia continue to be difficult and much further treatment may be necessary. It seems reasonable to say that all cases can eventually be brought into a stable state where dysphagia although not cured is not an insuperable problem. The last question is the easiest to answer. The operation is certainly well tolerated and there seems no reason why the operative mortality should not be well under $5 \%$ with minimal dangers of complications.

\section{SUMMARY}

The operation of gastroplasty has been re-appraised.
Some facts arising from the follow-up of 30 patients have been noted.

No exaggerated claims are made, but a very fair degree of improvement in the patient's symptoms may be confidently expected.

It is suggested that, when surgical treatment is needed for patients with hiatus hernia and short oesophagus, gastroplasty is the method of choice.

My thanks are due to Mr. T. F. Dee, of the Photographic Department of the Queen Elizabeth Hospital, Birmingham, for the care he has taken with the radiographic reproductions.

\section{REFERENCES}

Allison, P. R. (1951). Surg. Gynec. Obstet., 92, 419. Bingham, J. A. W. (1958). Brit. med. J., 2, 817.

Collis, J. L. (1957a). Thorax, 12, 181.

- (1957b). J. thorac. Surg., 34, 768.

- (1961). Thorax, 16, 114.

- Kelly, T. D., and Wiley, A. M. (1954). Ibid., 9, 175

Rapant, V., and Schwarzer, M. (1960). Cas. Lék. ces., 99, 946. 